\title{
Aplikasi Radien untuk Pengolahan Data Rekam Medis dengan Microsoft Visual Studio 2010
}

\author{
Shavira Handayan Putri*, Yuda Syahidin, Meira Hidayati \\ Program Studi Informatika Rekam Medis, \\ Politekinik Piksi Ganesha, Bandung, \\ Jawa Barat, INDONESIA \\ shputri@piksi.ac.id*,yuda.syahidin@piksi.ac.id, meira.hidayati@piksi.ac.id
}

\begin{abstract}
This study aims to design an integrated patient development record complete information system at Bina Sehat General Hospital in Bandung. The research method that the author used in this research is a use qualitative research method with a descriptive approach. And for the software method used by the author in this study, the Waterfall development method is used. From the results of the research that has been done by the author, it was found, including the processing of the integrated patient development record completeness system that was running less effectively, there was still incomplete integrated patients' development record. Therefore, the authors designed an information system the completeness of patient progress record integrated with the programing language used was Microsoft Visual Studio 2010, and the database used was Microsoft Access 2016. The suggestion that the author gave was the need to develop an integrated patient development record complete information system to facilitate processing the required information, the need for socialization about filling out patient progress record integrated to all officers.
\end{abstract}

\section{Keywords: Design; Integrated Patient Progress Record; Waterfall.}

ABSTRAK - Penelitian ini bertujuan untuk merancang sistem informasi kelengkapan catatan perkembangan pasien terintegrasi di Rumah Sakit Umum Bina Sehat Bandung. Metode Penelitian yang digunakan dalam Penelitian ini yaitu dengan Metode penelitian kulitatif dengan pendekatan deskriptif. Dan untuk Metode perangkat lunak yang digunakan dalam Penelitian ini yaitu dengan Metode pengembangan $W$ aterfall. Dari hasil penelitian yang telah dilakukan ditemukan beberapa masalah dantaranya adalah: pengolahan sistem kelengkapan catatan perkembangan pasien terintegrasi berjalan kurang efekif, masih adanya catatan perkembangan pasien terintegrasi yang belum lengkap. Oleh karena itu penelitian ini merancangan sistem informasi kelengkapan catatan perkembangan pasien terintegrasi dengan bahasa pemograman yang digunakan adalah Microsoft Visual Studio 2010 dan database yang digunakan adalah Microsoft Access 2016. Penelitian ini telah dilakukan namun ada beberapa hal yang dapat disaran yaitu perlu adanya pengembangan sistem informasi kelengkapan catatan perkembangan pasien terintegrasi untuk mempermudah dalam pengolahan informasi yang dibutuhkan, juga perlunya sosialisasi tentang pengisian catatan perkembangan pasien terintegrasi keseluruh petugas.

Kata Kunci: Perancangan; Catatan Perkembangan Pasien Terintegrasi; Waterfall.

\section{Pendahuluan}

Tercapainya pembangunan kesehatan akan menentukan tercapainya tujuan kesehatan nasional. Kemajuan kesehatan yang berencana untuk lebih mengembangkan status kesehatan masyarakat serta meningkatkan dan mengembangkan pelayanan kesehatan di Rumah sakit. Dengan demikian, agar peningkatan kesehatan dapat dikoordinasikan dan dipusatkan pada satu tujuan yang dinginkan dengan memahami tingkat derajat kesehatan setinggi-setingginya, maka perlu memiliki referensi pengaturan sebagai pembantu pelaksanaannya. Sistem informasi kesehatan adalah sistem pengelolaan data dan informasi kesehatan berbasis komputeri yang terintegrasi yang bertujuan untuk mempermudah peningkatan pelayanan kesehatan di rumah sakit.

Berdasarkan Undang-Undang Republik Indonesia Nomor 44 Tahun 2009 tentang Rumah Sakit menyebutkan bahwa rumah sakit adalah institusi pelayanan kesehatan perorangan secara paripurna yang menyediakan pelayanan rawat inap, rawat jalan dan gawat darurat. Setiap sarana pelayanan kesehatan wajib membuat rekam medis yang dibuat oleh dokter dan tenaga kesehatan yang terkait dengan pelayanan yang diberikan [1].

Menurut Permenkes No. 269/ Menkes/ Per/ III/ 2008 rekam medis adalah "berkas yang berisi catatan dan dokumen antara lain identitas pasien, hasil pemeriksaan, pengobatan yang telah diberikan, serta tindakan dan pelayanan lain yang telah diberikan kepada pasien. Catatan merupakan tulisan-tulisan yang dibuat oleh dokter atau dokter gigi mengenai tindakan-tindakan yang dilakukan kepada pasien dalam rangka pelayanan kesehatan" [2]. Rekam Medis merupakan berkas yang penting dalam pelayanan kesehatan karena ddalamnyai terdapat data pasien yang sewaktu-waktu dibutuhkan saat pasien berobat kembali [3]. 
Perancangan sistem adalah proses penerjemahani kebutuhan pengguna informasi ke dalam suatu rancangan untuk memenuhi kebutuhan pemakai dan pemberi gambaran yang lebih jelas untuk dijadikan pertimbangan [4]. Analisis kelengkapan isi berkas rekam medis merupakan hal yang sangat penting, dan yang bertanggung jawab untuk mengisi berkas rekam medis tersebut yaitu dokter dan perawat yang telah bertanggung jawab merawat pasien di rumah sakit. Menurut [5] definisi kelengkapann rekam medis adalah "kajian/telaah isi rekam medis berkaitan dengan pendokumentasian, pelayanan dan atau menilai kelengkapan rekam medis".

Catatan perkembangan pasien terintegrasi yaitu pendokumentasi yang dilakukan oleh dokter dan perawat tentang kemajuan kondisi pasien dalam format terpadu dan bentuk standar di dalam Rekam medis pasien dengan dengan metode SOAP berdasarkan pengkajian Subjektive, Objektive, Assessment, dan Plan.

Tujuan dari penulisan pada CPPT agar perkembangan kesehatan pasien dapat terpantau dan berkesinambungan antara dokter, perawat atau asuhan pelayanan pasien lainnya dan dikumpulkan di dalam rekam medis pasien. Hal ini menjadikan akhir dari perawatan pasien menjadi bermutu dan terukur.

Berdasarkani analisisi yang telahi dilakukani penulisi terhadapi sistem analisis kelengkapan catatan perkembangan pasien terintegrasi yang sedang telah ada saat ini, maka diperlukan adanya penggunaan sistem yang lebih unggul dari sistem yang telah ada saat ini di Rumah Sakit tersebut yaitu dengan merancang dan mengaplikasikan sistem yang terkomputerisasi dan berbasis database agar mempermudah proses pengecekan kelengkapan rekam medis pasien di rumah sakit yang secara otomatis, akurat, cepat dan tepat serta mempermudah perhitungan persentase kelengkapan catatan perkembangan pasien terintegrasi tersebut.

Analisis kelengkapan isi berkas rekam medis dilakukan di ruang rekam medis oleh petugas assembling.
Berdasarkan pengamatan yang dilakukan selama praktek kerja lapangan di Rumah Sakit Umum Bina Sehat Bandung terdapat beberapa permasalah yang ditemui dantaranya, petugas assembling menemukan banyak pengisian formulir catatan perkembangan pasien terintegrasi ini yang tidak lengkap, karena Standar Operasional Prosedur (SOP) belum terlaksana dengan baik, dan kurang adanya kerjasama dantara dokter dan perawat dalam pengisian formulir catatan perkembangan pasien terintegrasi.

\section{Metodologi}

Dalam menyelesaikan penelitian ini metode yang digunakan untuk merancang sistem informasi kelengkapan catatan perkembangan pasien ini dengan penelitian kualitatif dengan pendekatan deskriptif dengan menjelaskan keadaan yang terjadi di lapangan khususnya mengenai analisis kelengkapan catatan perkembangan pasien terintegrasi di Rumah Sakit Umum Bina Sehat Bandung yang kemudian membuat perancangan sistem informasi kelengkapan catatan perkembangan pasien terintegrasi. Menurut [6] metode penelitian kualitatif adalah metode yang digunakan untuk meneliti kondisi objektif yang alamiah dimana peneliti adalah sebagai instrumen kunci, teknik penelitian data dilakukan secara gabungan, analisis data bersifat induktif/kualitatif, hasil penelitian lebih menekankan pada makna generalisasi. Menurut [7] metode penelitian deskriptif adalah suatu metode ipenelitain yang dilakukan dengan tujuan utama untuk membuat gambaran atau deskripsi tentang keadaan secara objektif.

Metode pengembangan perangkat lunak yang digunakan dalam penelitian ini adalah metode $W$ aterfall. Menurut [8] model Waterfall adalah model klasik yang bersifat sistematis, berurutan dalam membangun Software. Tahapan dalam $W$ aterfall model menurut Pressman yaitu:

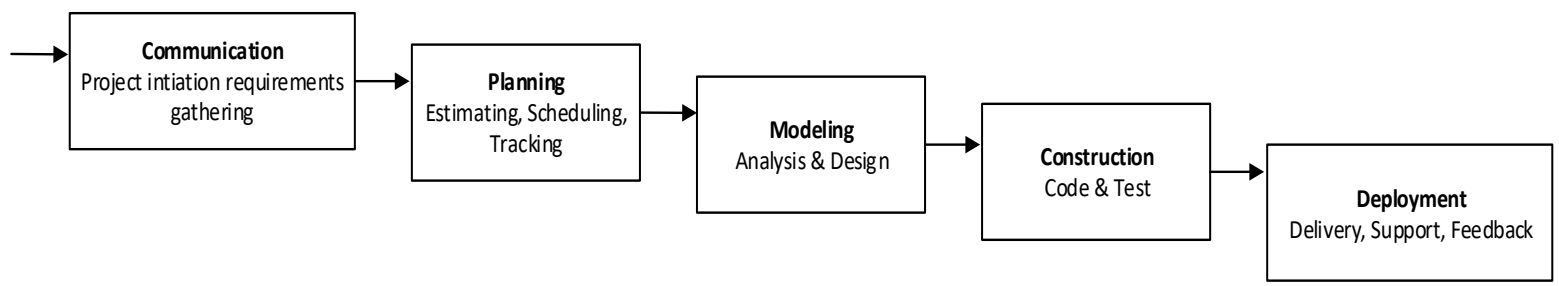

Gambar 1. Metode Waterfall

\section{Hasil dan Pembahasan}

Analisis sistem akan memberikan gambaran tentang sistem yang saat ini sedang berjalan dan bertujuan untuk mengetahui lebih jelas bagaimana cara kerja atau rancangan sistem tersebut serta untuk mendefinisikan dan mengevaluasi permasalahan yang terjadi dan kebutuhan-kebutuhan yang diharapkan dapat diusulkan suatu perbaikan.

Analisis sistem yang sedang berjalan dengan dengan Diagram Konteks, Flowmap, dan Data Flow Diagram (DFD) seperti dibawah ini:
1) Flow map yang sedang berjalan di Rumah Sakit, Gambar 2.

2) Diagram Konteks yang sedang berjalan di Rumah Sakit, Gambar 3.

3) Data Flow Diagram (DFD) Level 0 yang sedang berjalan di Rumah Sakit, Gambar 4.

Dalam perancangan aplikasi ini upaya yang diusulkan perancangan aplikasi dengan dengan Flowmap, Diagram Konteks, Data Flow Diagram (DFD), Entity Relationship Diagram (ERD), dan tabel Relasi seperti berikut. 


\section{A. Flow map yang Diusulkan}

Flow map secara umum adalah kombinasi antara peta dengan Flowchart, yang menunjukan pergerakan alur benda dari suatu area ke area lain. Flow map membantu para ahli dan programmer perangkat lunak memisahkan masalah menjadi bagian-bagian yang lebih sederhana dan menyelidiki pilihan dan aktivitas. Gambar 5 Flow map yang diusulkan.

\section{B. Diagram Konteks yang Diusulkan}

Diagram konteks adalah diagram yang terdiri dari suatu proses dan menggambarkan ruang lingkup suatu sistem. Diagram konteks merupakan level tertinggi dari DFD yang menggambarkan seluruh input ke sistem baru output dari sistem kemudian memberikan gambaran tentang keseluruhan sistem. Sistem dibatasi boundary (dapat digambarkan dengan garis putus). Dalam diagram konteks hanya ada satu proses. Tidak boleh ada store dalam diagram konteks [9]. Gambar 6 Diagram Konteks yang diusulkan.

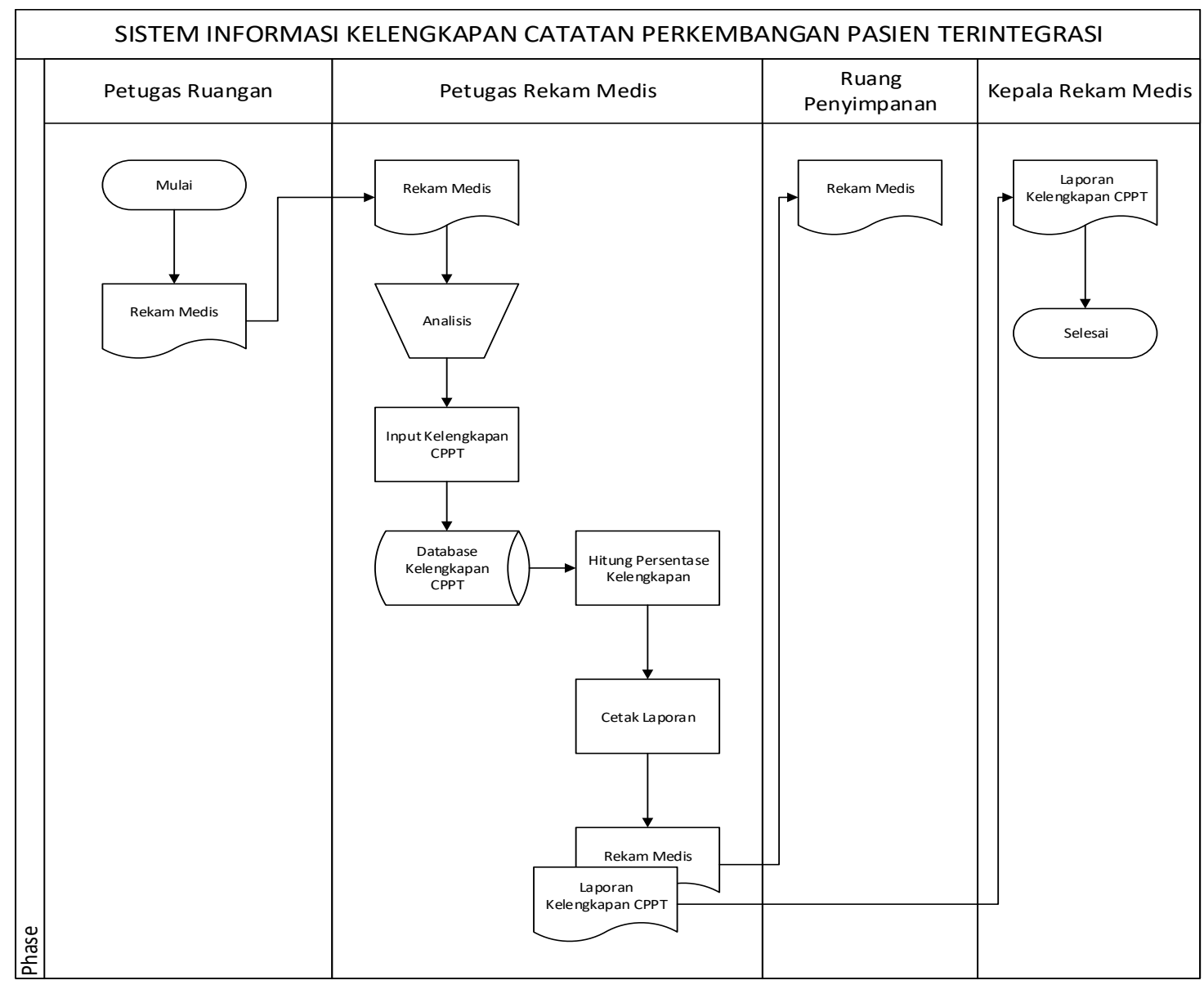

Gambar 2. Flow map yang Sedang Berjalan di Rumah Sakit

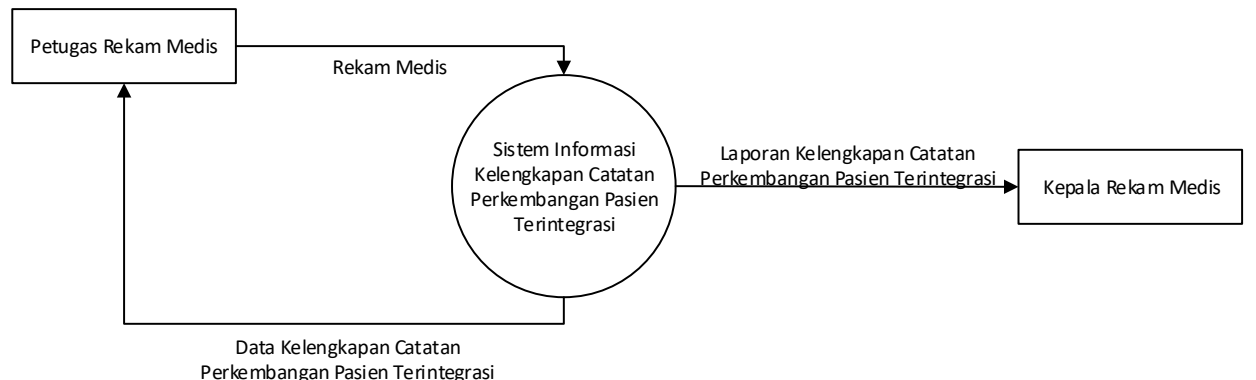

Gambar 3. Diagram Konteks yang Sedang Berjalan di Rumah Sakit 


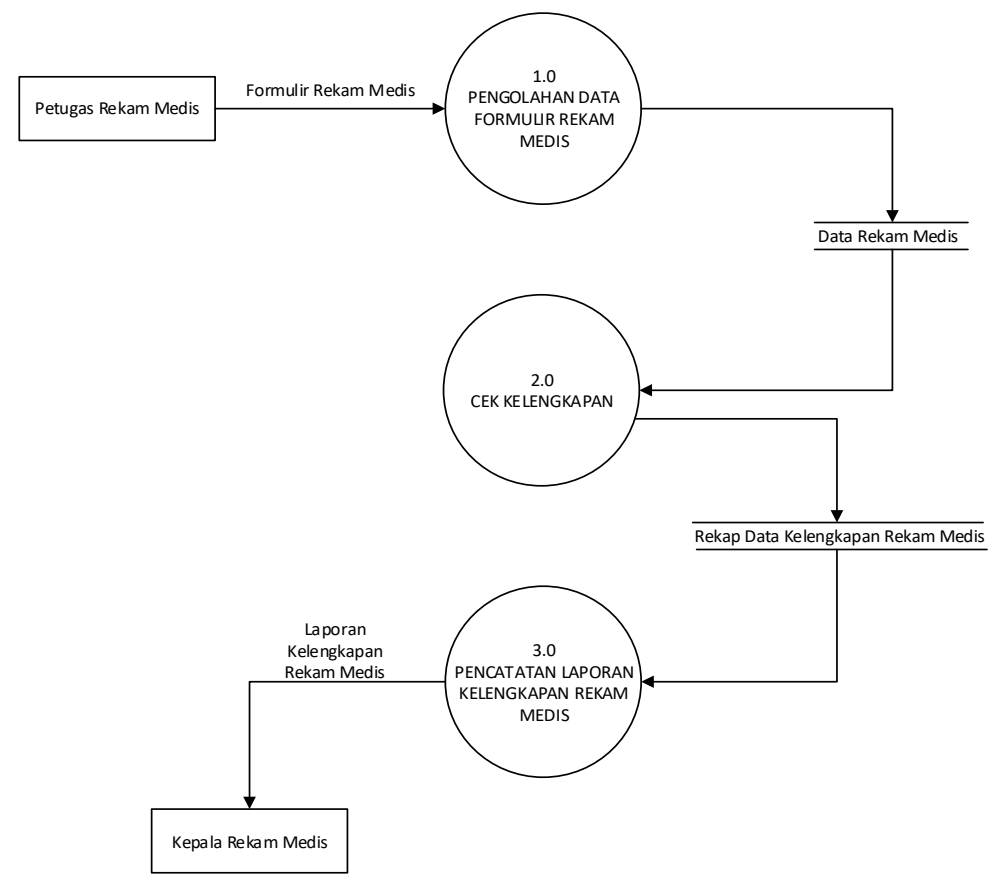

Gambar 4. DFD Level 0 yang Sedang Berjalan di Rumah Sakit

\section{Data Flow Diagram (DFD) yang Diusulkan}

Data Flow Diagram (DFD) merupakan model dari sistem untuk menggambarkan ipembagian sistem ke modul yang lebih kecil [9]. Diagram nol adalah Diagram yang menggambarkan proses dari Data Flow Diagram.
Diagram nol memberikan perspektif lengkap tentang kerangka kerja yang ditangani, menunjukan kapasitas tentang fungsi-fungsi utama atau siklus yang ada, aliran data dan eksternal entry. Gambar 7 Data Flow Diagram Level 0 yang diusulkan.

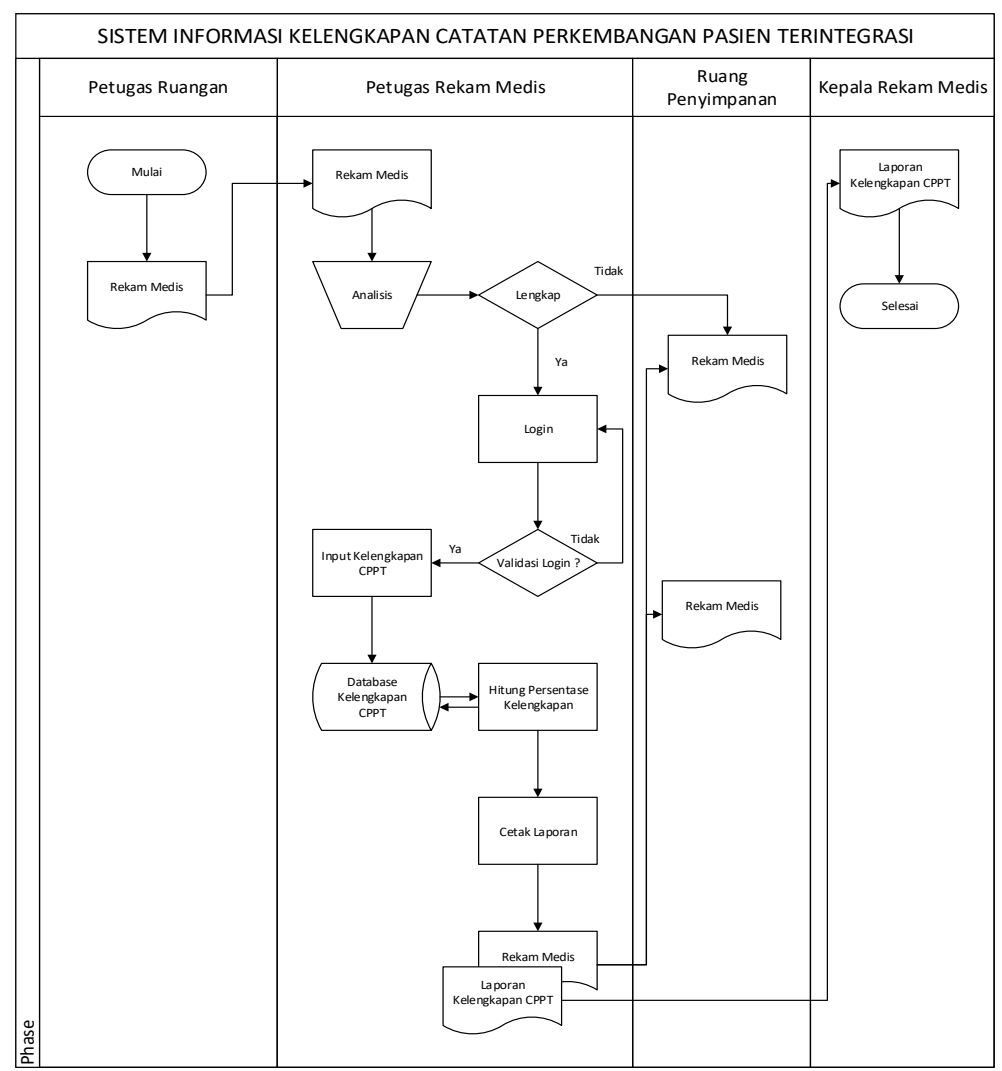

Gambar 5. Flow map yang Diusulkan 


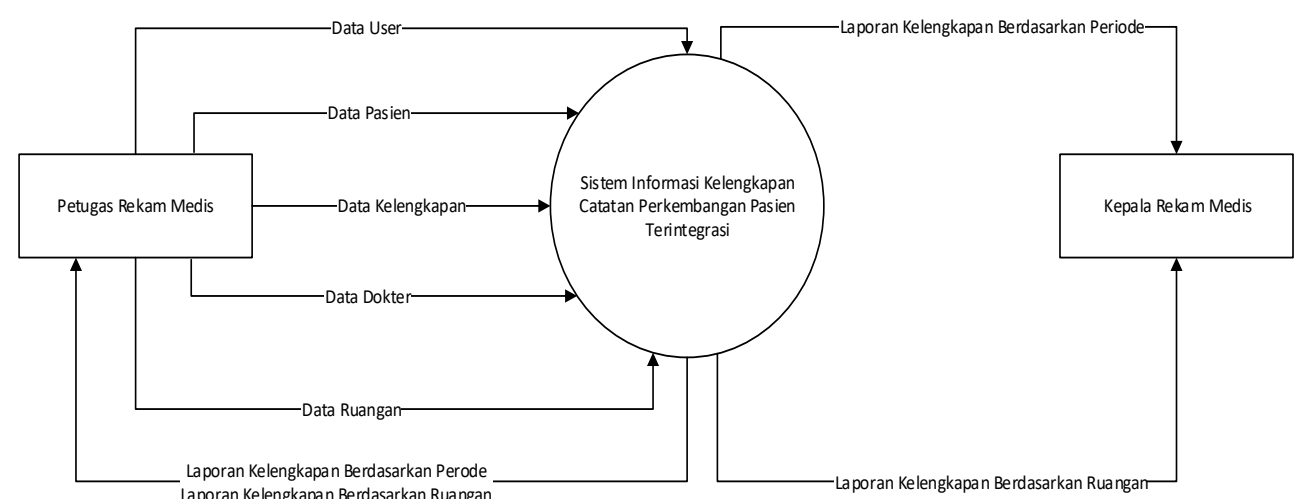

Gambar 6. Diagram Konteks yang Diusulkan

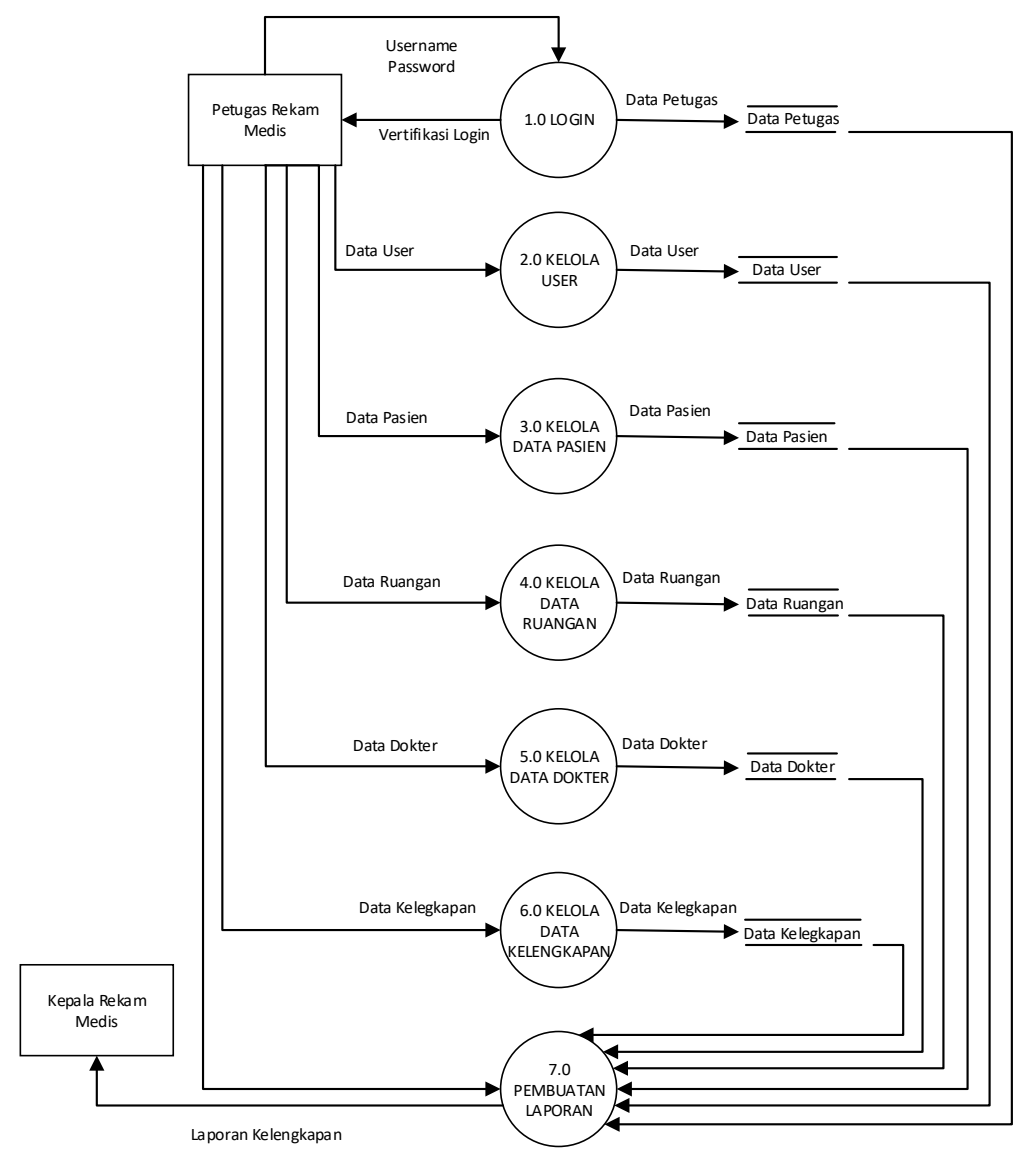

Gambar 7. Data Flow Diagram Level 0 yang Diusulkan

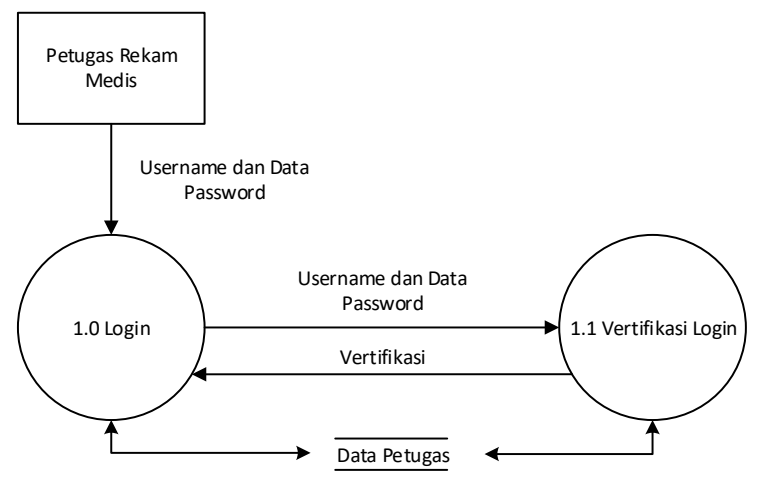

Gambar 8. Data Flow Diagram Level 1 Proses 1.0 yang Diusulkan 


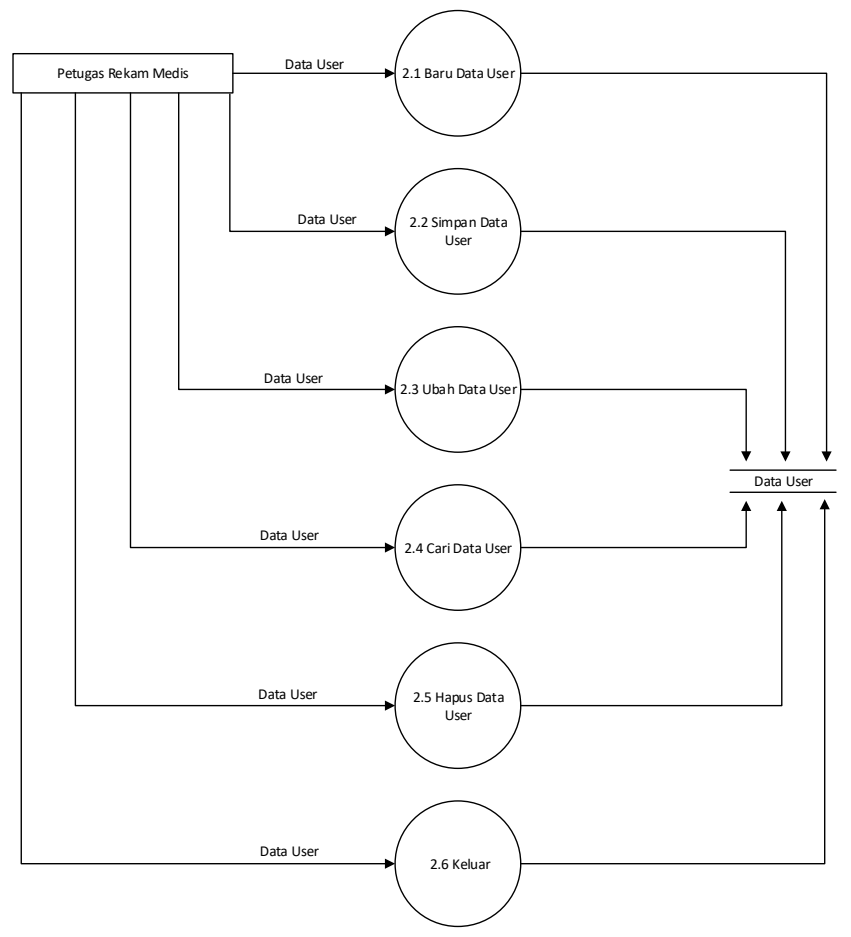

Gambar 9. Data Flow Diagram Level 1 Proses 2.0 yang Diusulkan

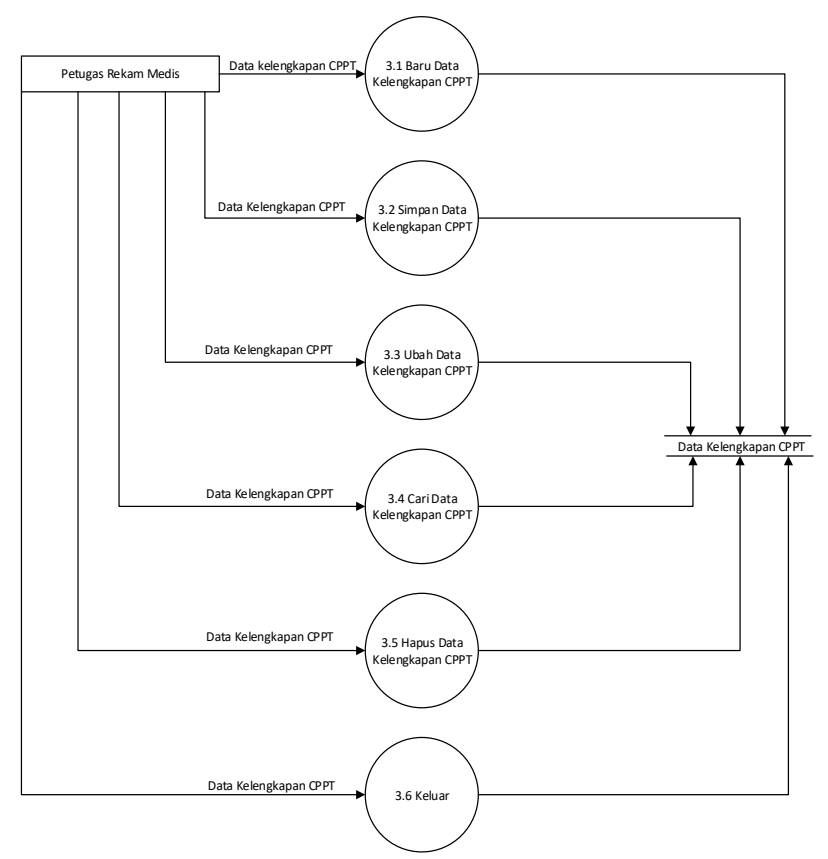

Gambar 10. Data Flow Diagram Level 1 Proses 3.0 yang Diusulkan

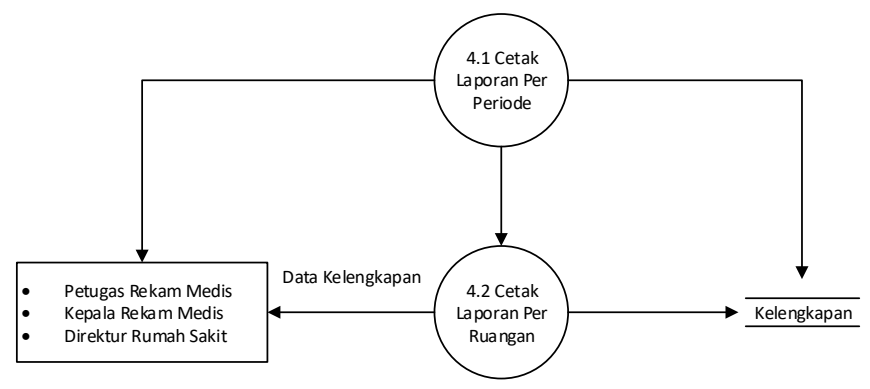

Gambar 11. Data Flow Diagram Level 1 Proses 4.0 yang Diusulkan 


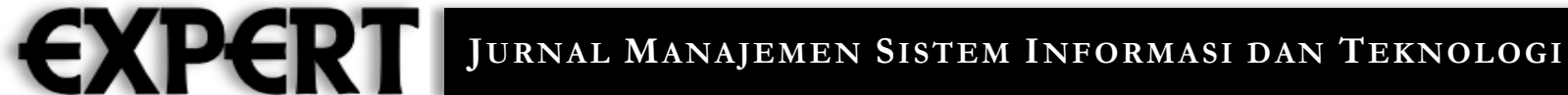

\section{Entity Relationship Diagram yang Diusulkan}

Entity Relationship Diagram (ERD) adalah teknik yang digunakan untuk memodelkan Data dalam kebutuhan
Data suatu organisasi, biasanya digunakan untuk analisis sistem. Pada tahap analisis ini merupakan kebutuhan proyek untuk mengembangkan sistem [10].

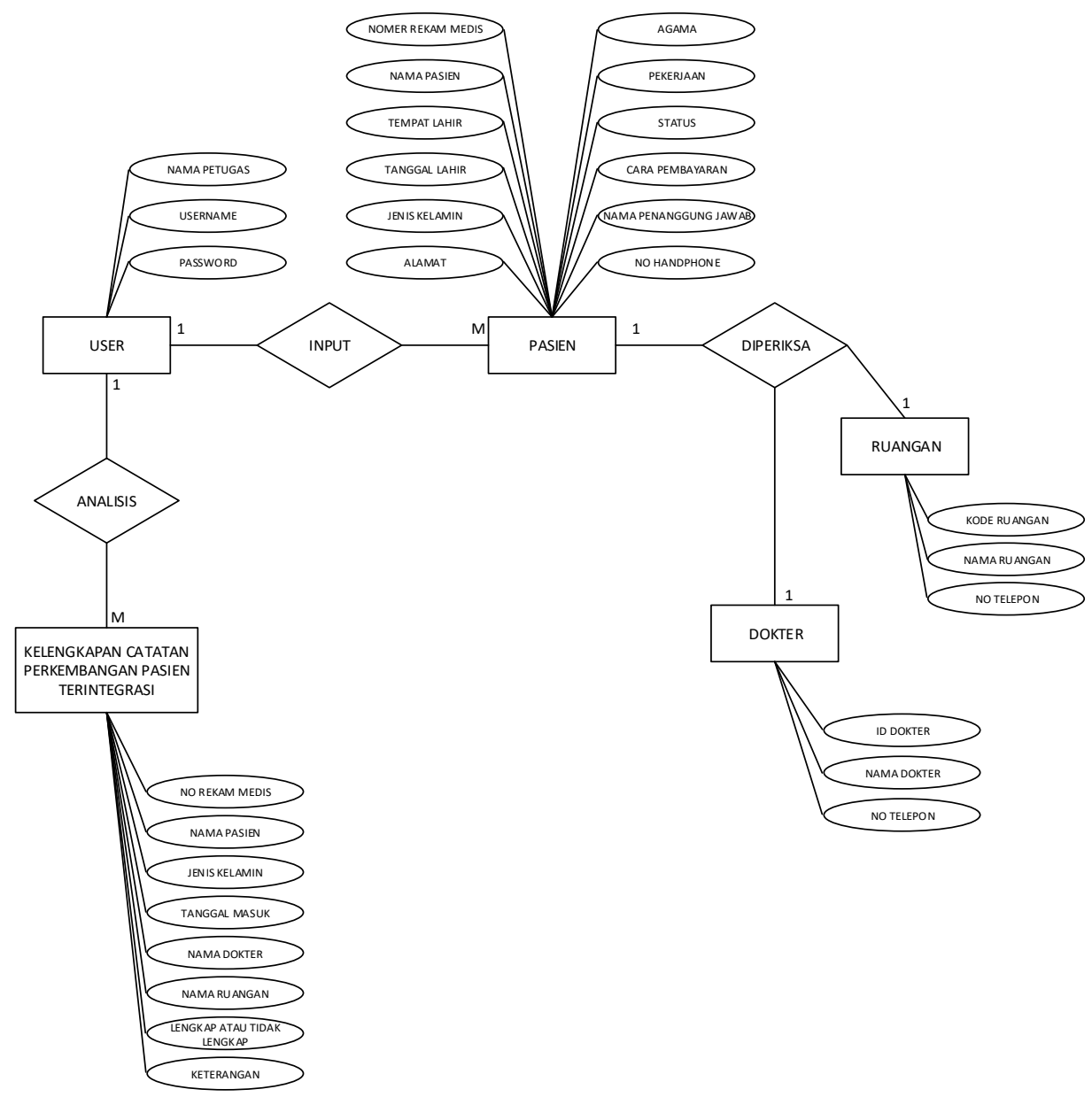

Gambar 12. ERD yang Diusulkan

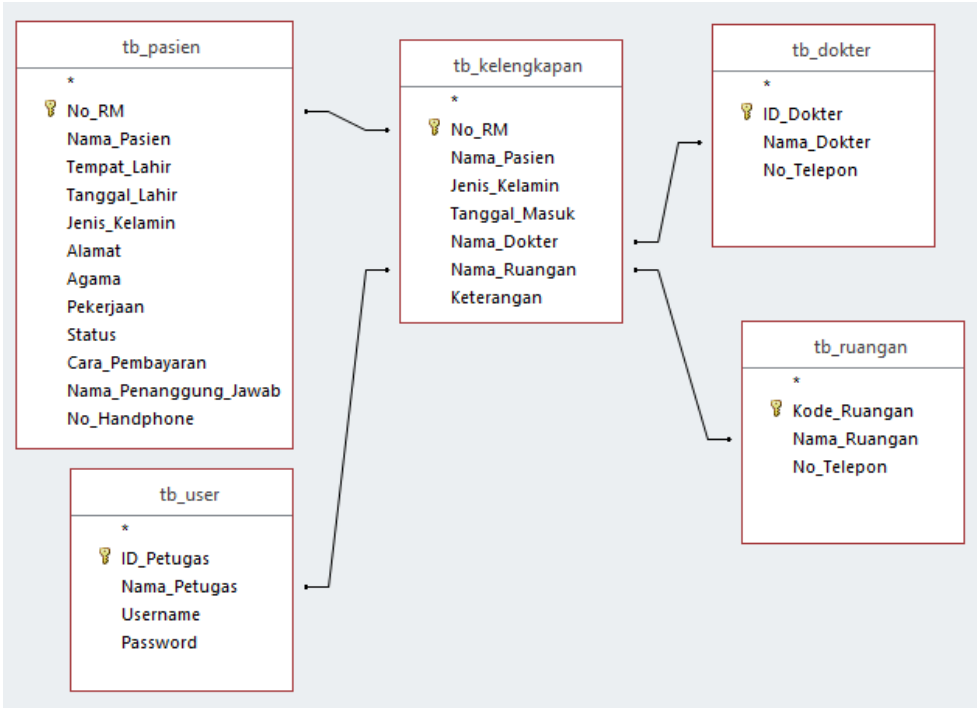

Gambar 13. Relasi Tabel yang Diusulkan 


\section{E. Spesifikasi Hardware dan Software}

Perangkat keras (Hardware) adalah semua komponen peralatan yang membentuk suatu sistem dan peralatan lain yang memungkinkan komputer untuk melaksanakan tugasnya secara fisik dan dapat dilihat secara jelas dan nyata. Perancangan sistem informasi catatan perkembangan pasien terintegrasi ini membutuhkan spesifikasi yaitu; (a) Processor Intel(R) Celeron(R) CPU N3350@1.10GHz 1.10 GHz; dan (b) RAM 2,00 GB. Sedangkan Perangkat lunak (Software) yang dibutuhkan yaitu; (a) Sistem operasi Windows 10; (b) Bahasa Pemograman Visual Studio 2010; dan (c) Database Microsoft Acces 2016.

\section{F. Implementasi Sistem}

Pembuatan perancangan suatu sistem yang dibuat dengan menggunakan aplikasi Microsoft Visual Studio 2010 dengan dengan Database Microsoft Access 2016. Berikut adalah penjelasan dari program tersebut.

Sistem ini memiliki menu Login untuk bisa mengakses ke menu utama. Design menu Login bisa di lihat pada Gambar 14.
Selanjutnya terdapat menu utama yang menampilkan menu file, master data dan laporan. Dalam menu file berisikan login, logout dan register. Lalu ddalam menu master data berisikan data kelengkapan pasien. Dan ddalam menu laporan berisikan laporan apa saja yang sedang dibutuhkan. Design menu utama bisa dilihat pada Gambar 15.

Selanjutnya terdapat form daftar user yang berfungsi untuk mendaftarkan nama petugas agar petugas bisa dengan sistem tersebut. Design menu daftar user bisa di lihat pada Gambar 16.

Selanjutnya terdapat form kelengkapan, form ini digunakan untuk petugas rekam medis menginput data kelengkapan pasien. Design menu data kelengkapan bisa di lihat pada Gambar 17.

Selanjutnya adalah form laporan yang fungsinya untuk memfilter laporan apa saja yang harus ditampilkan. Design menu laporan bisa di lihat pada Gambar 18. Pada Gambar 19 adalah tampilan laporan yang sudah ditampilkannya.

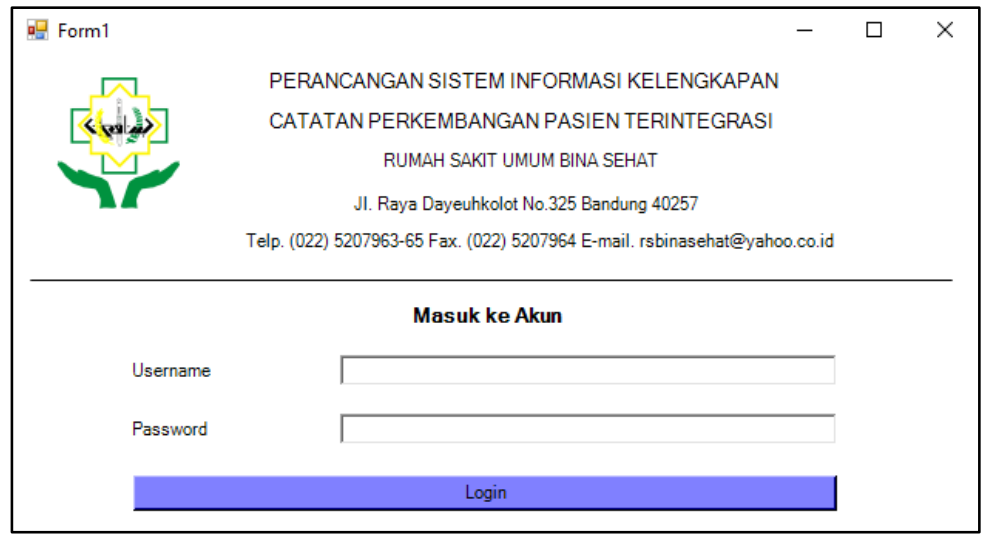

Gambar 14. Form Menu Login

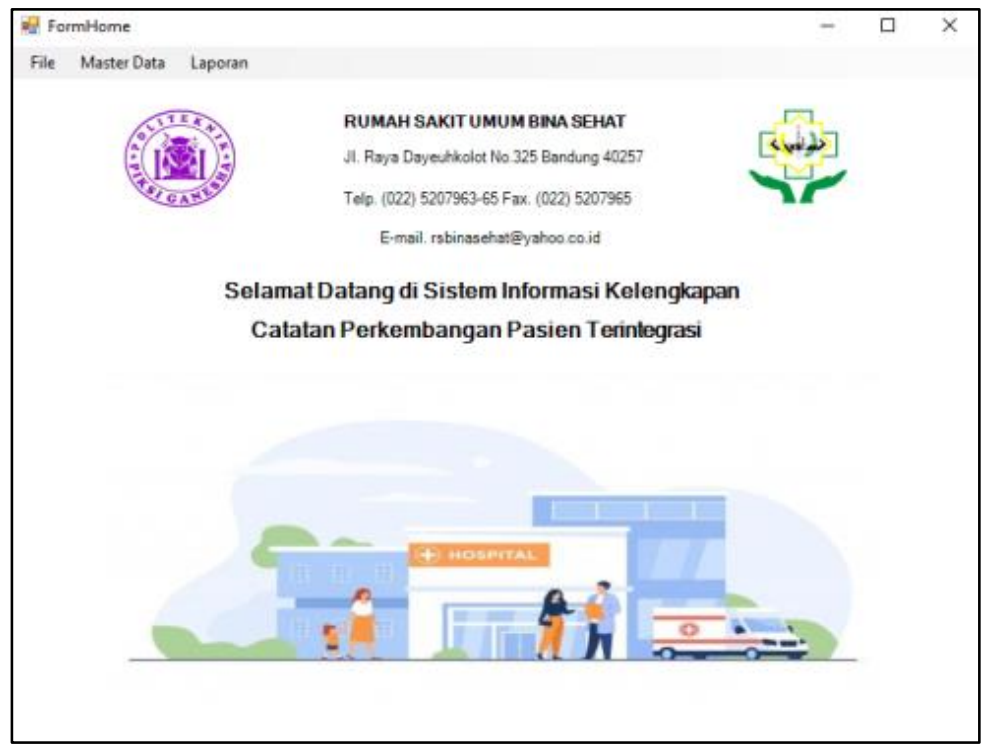

Gambar 15. Form Menu Home 


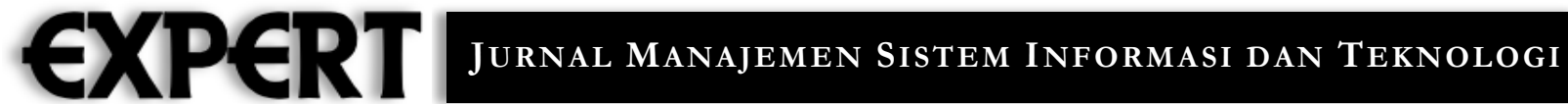

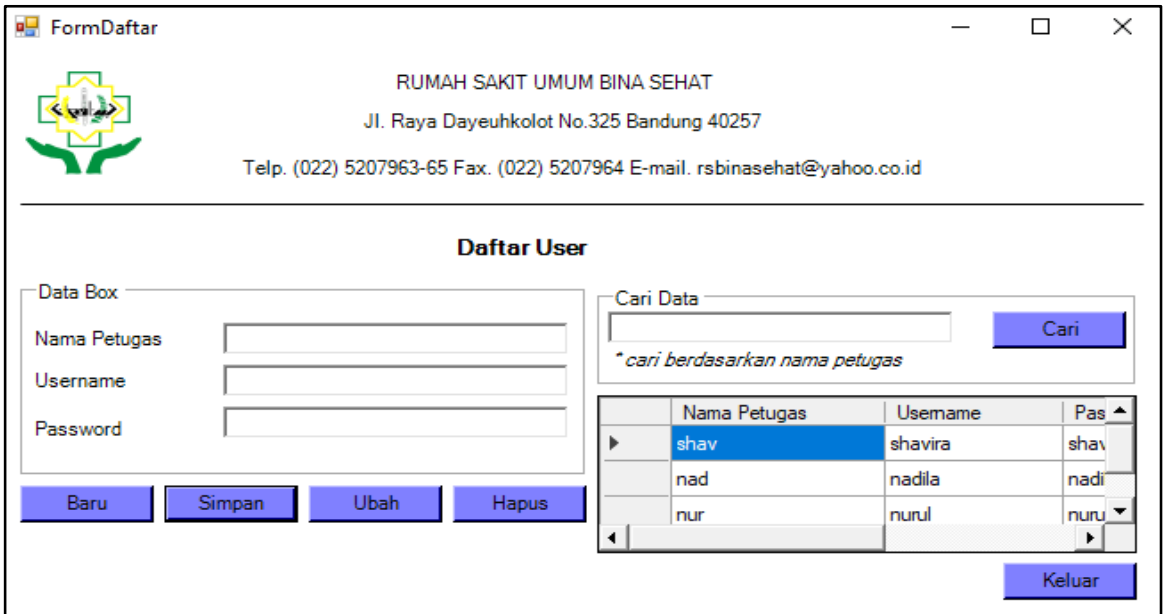

Gambar 16. Form Menu Daftar User

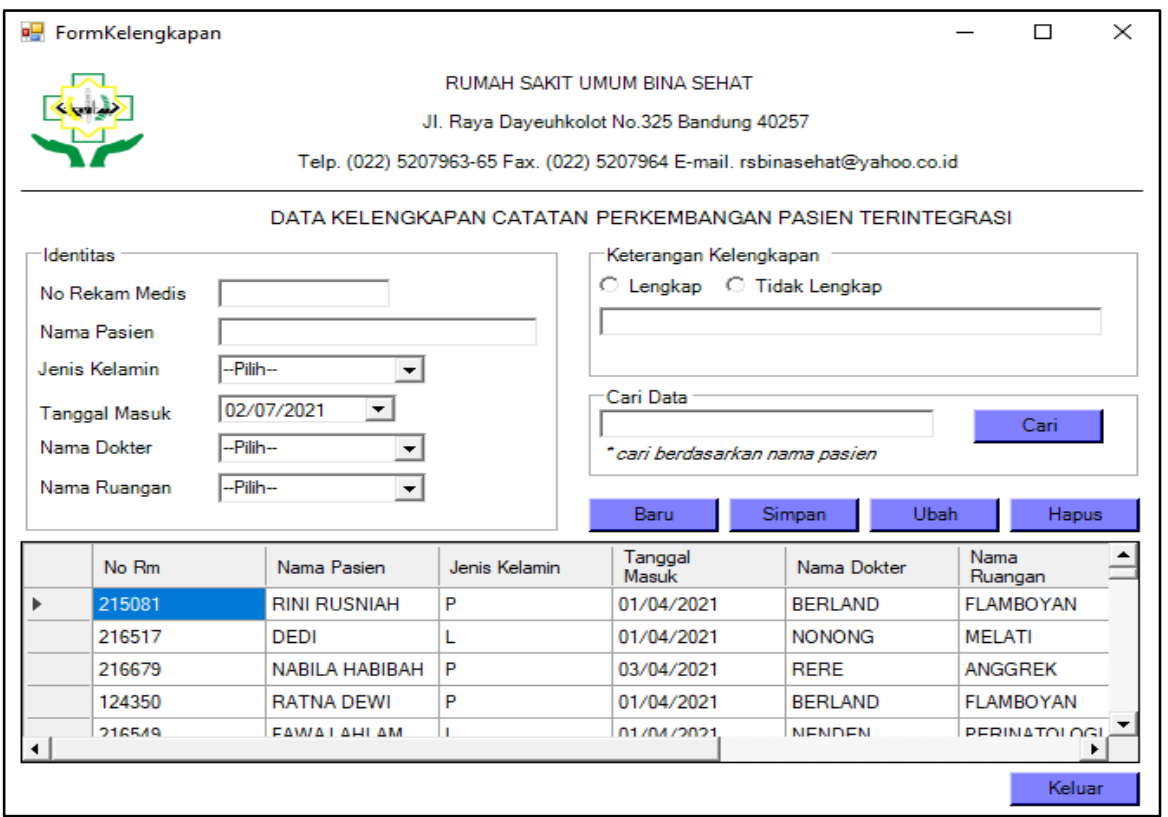

Gambar 17. Form Data Kelengkapan

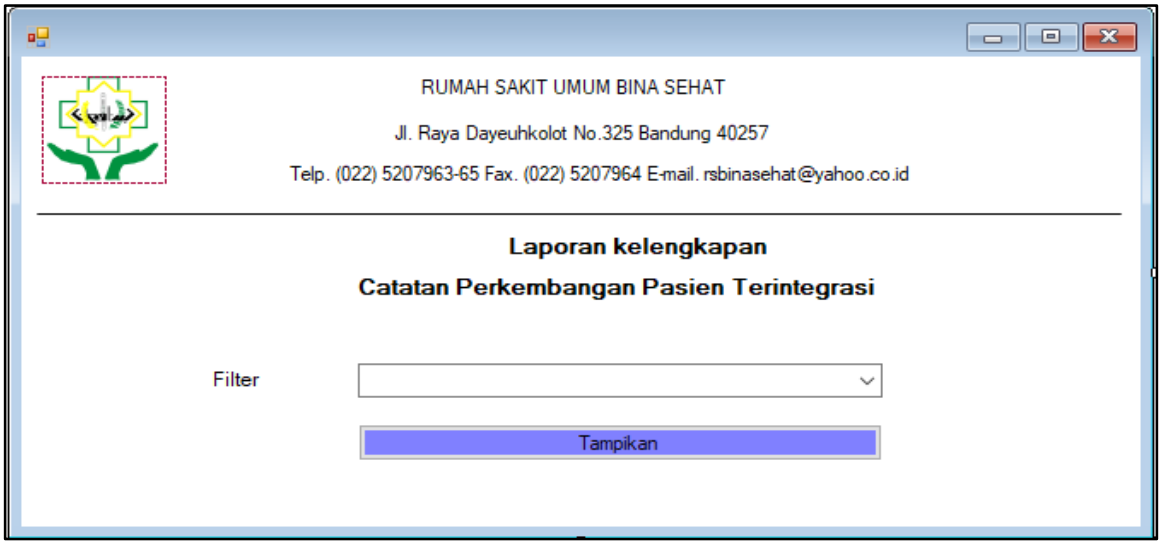

Gambar 18. Form Laporan 


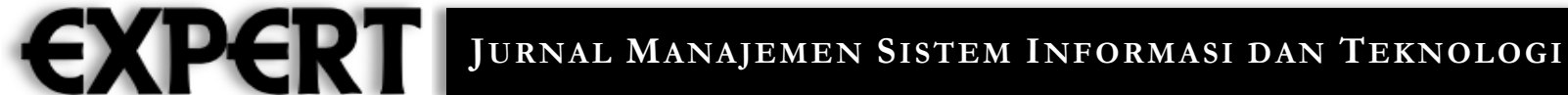

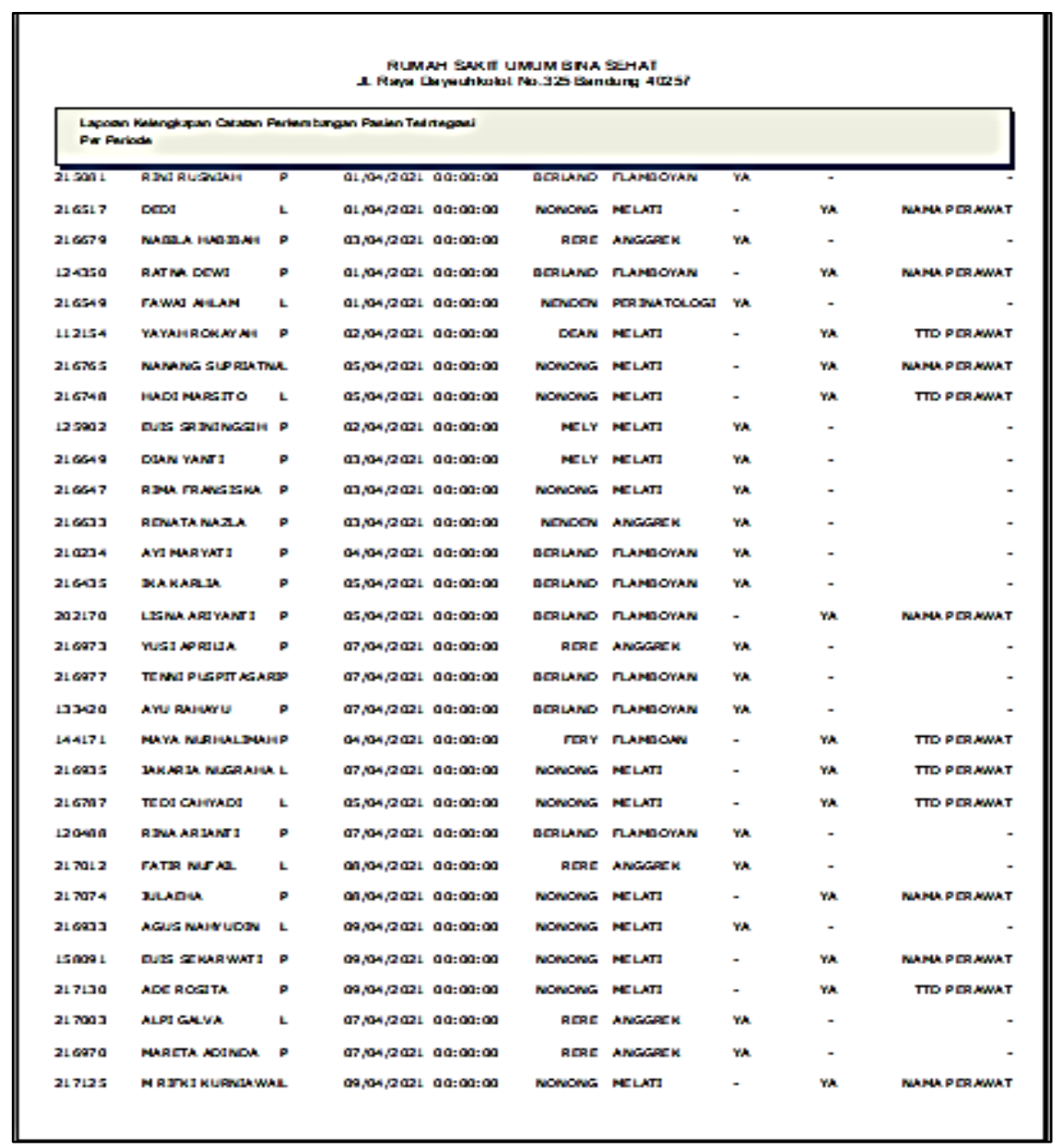

Gambar 19. Form Laporan per Periode

\section{Kesimpulan}

Berdasarkan penelitian yang telah dilakukan oleh di Rumah Sakit Umum Bina Sehat Bandung, kesimpulan yang dapat diberikan adalah Aplikasi yang telah dirancang ini dapat diusulkan untuk membantu pihak Rumah Sakit Umum Bina Sehat Bandung dalam mengolah analisis kelengkapan formulir catatan perkembangan pasien terintegrasi secara komputerisasi. Proses perancangan sistem informasi kelengkapan catatan perkembangan pasien terintegrasi dengan metode Waterfall dan penggambaran fungsional sistem dengan bahasa Pemograman Microsoft Visual Studio 2010. Dan cara yang tepat untuk mengatasi masalah yang terjadi di Rumah Sakit Umum Bina Sehat Bandung adalah dengan cara mengimplementasikan program yang telah dirancang dengan Microsoft Visual Studio 2010 dan Database Microsoft Acces 2016

\section{Daftar Pustaka}

[1] Republik Indonesia, "UU RI nomor 44 tahun 2009 tentang Rumah Sakit", Jakarta, 2009.

[2] Peraturan Menteri Kesehatan RI, "Nomor 269/MENKES/PER/III/2008 tentang Rekam Medis", Jakarta, 2008.
[3] S. S. Y. Syahidin, "Perancangan Sistem Informasi Penyimpanan Rekam Medis Rawat Inap Berbasis Elektronik," Jurnal Manajemen Informasi Kesehatan Indonesia, vol. 5, 2017.

[4] L. S. E. E. R. S. P. Sinaga, "Implementasi Sistem Inventori Hotel Morcopolo," Jurnal Manajemen Sistem Informasi dan Teknologi, vol. 7, 2017.

[5] H. Edna K, Health Information Management, Physician Record Compay. Berwyn: Illions, 1999.

[6] Sugiyono, Metode Penelusuran Kuantitatif, Kualitatif dan R\&D. Bandung, 2013.

[7] N. Soekidjo, Metodelogi Penelitian Kesehatan. Jakarta: Renika Cipta, 2010.

[8] P. R. S, Rekayasa Perangkat Lunak : Pendekatan Praktisi (buku dua). Yogyakarta: Penerbit Andi, 2015.

[9] Ladjamudin, Analisis dan Desain Sistem Informasi. Yogyakarta: Graha Ilmu, 2013.

[10] S. K. Tata Sutabri, Sistem Informasi Manajemen (edisi revisi). CV.Andi OFFSET, 2016.

DOI http://dx.doi.org/10.36448/expert.v11i2.2110 e-ISSN 2745-7265 p-ISSN 2088-5555 EXPERT Vol. 11 No. 2 December 27, 2021 - Hal. 122 